\title{
Beyond the mainstream
}

\author{
Helen Macdonald clinical editor
}

The BMJ

"There is very little science in shaken baby syndrome. It's become a label. We're not there at the time of collapse. We don't know if these babies have been shaken." So said Waney Squier, the neuropathologist struck off the medical register last week after a General Medical Council (GMC) tribunal found that she had deliberately misled the courts. In tens of court cases, Squier had spoken in defence of families accused of non-accidental head injury and against mainstream opinion on "shaken baby." But as Jacqui Wise reports, (doi:10.1136/bmj. i17126) the GMC tribunal ruled that she had failed to recognise the limits of her knowledge and competence in giving evidence, and failed to respect the skills and contributions of colleagues.

Many people, including the GMC's chief executive, Niall Dickson, question whether the council is the proper place to consider such debates. Wise reports that the Royal College of Paediatrics and Child Health is considering setting up a working group to examine the evidence on non-accidental head injury, as it did for sudden unexpected infant deaths in 2004.

Discussing Squier's case, Stephen Watkins (doi:10.1136/bmj. i1768) writes that doctors with dissenting opinions should be heard, but that they may not feel able to speak openly if they fear being struck off. Intolerance of opinions that run contrary to guidelines is a worry. Watkins describes wider issues.

"Shaken baby" is just one scenario where there is uncertainty, and the law is poorly equipped to consider scientific disputes. It's a longstanding problem and he writes that "after the miscarriages of justice surrounding cot death, the BMA called for a public inquiry headed by a doctor or a scientist into the judicial system's failure to cope with scientific controversy. That didn't take place. No lessons were learnt. Sooner or later more miscarriages of justice will result."

People, as well as ideas, can fall outside society's mainstream. Seeking a way into Britain, a group of destitute Iraqi Kurds are the main occupants of a new migrant camp at Dunkirk, built by Médecins Sans Frontières. The camp's windowless huts have access to communal water and electricity, and provide healthier conditions for the group. Sophie Arie (doi:10.1136/bmj.i1696) hears from staff and migrants about their medical needs. Injuries are common. Residents are given a medical card, and Arie reports on some optimism in the camp. "There were no cases of burns in the 10 days after the camp opened and doctors said that they had seen fewer cases of scabies and serious respiratory infections."

As for transgender people, their needs for referral and medication are understood by specialists working in gender identity but may be incompletely delivered by others. Consultant James Barrett shares anecdotal accounts (doi:10.1136/bmj.i1694) of GPs raising concerns that hormonal drugs for transgender people may be dangerous, difficult, or expensive to prescribe. Better understanding of the evidence base and the model of shared care that he describes may help. Barrett writes that, "I've also heard disturbingly frank admissions that it was "against deeply held Christian beliefs" or that "we are trained to treat illness, not to change nature." These attitudinal barriers may be harder to shift. 